\title{
EXPERIÊNCIA INTERNACIONAL DO ENSINO DE TURISMO E HOTELARIA Modelos para Avaliação
}

\author{
Mário Carlos Beni ${ }^{1}$
}

\begin{abstract}
RESUMO: Alonda o ensino em Turismo e Hotclaria. dcstacando a formaçăo superior nessas áreas, em vários países da liuropa. $\Lambda$ mérica do Norte e América Latina. Destaca a tendência de intcinacionalização do ensino superior e a importáncia de um intercâmbio permancentc entre os centros educacionais. Situa. dentro desse panorama mundial. a posiçăo brasileira do ensino em Turismo e Hotelaria.
\end{abstract}

PALAVRAS-ChAVE: Turismo e Hotelaria: cnsino: formaçăo de recursos humanos: formação superior.

ABSTRACT: the approach is in Turism and Hotel Bussincss, foncusing the higher cducation in thesc arcas in seleral coumerics in liturens; North America and Latin Ancrica. The tendency for the higher celucation internacionalization and the necessing of a pormancm infonmation interchange annong the Edecational Centers. Defincs the Brazilian position, in cemns of Turism and Hotel Busincss tcaching, in this worldwide scenan:

KEY WORDS: Turisin and Hotel Busincss: teaching: human resontres fonneation; highter education.

\section{INTRODUÇÃO}

A formação superior de turismo passa a scr importantc objeto de discussão em congressos curopeus a partir de 1\%4, na Espanha, onde foram analisados seus problemas cconômicos, lécnicos c suas relaçōes

1 Livre Docente e Professor Associado do Curso de Turismo da liscola de (omunicações e Artes da LSP. Delcgado para o Brasil da $\wedge$ MFOR'] - Associaçāo Mundial para a Formaçăo Profissional Turística.

End. para corresp.: ECA/USP - Depto. de Relaçőes Pihlicas. Propaganda c Turismo Cidade Universitária "Armando de Salles Oliveira" - $\Lambda v$. Prof. I úcio Martins Rodrigues, 443 - Bloco B - 05508-9(10 - São Paulo - SI' - Brasil. 
sociais. Na década de 198(), a Universidade Livre de Berlim (Ocidental elaborou modelo de estudo complementar em turismo, com o que um novo currículo de formação para especialistas em lurismo c markeling foj aprovado.

Os sćrios desafios no campo da economia do turismo exigem formação e aperfciçoamento contínuos, conforme assinala ( professor Loy Puddu $^{2}$, baseado na estimativa da ()rganização Mundial do Trabalho de que 100 milhōes de trabalhadores scrāo neccssários para garantir o funcionamento do setor de turismo no futuro. Baseados nesse número, já pode-se antecipar a problemática a enfrentar nos próximos anos, tanto do ponto de vista quantitativo, quanto sob o aspectu qualitative da formaçāo da māo-de-obra.

Hoje, as maiores demandas sāo fcitas sobre o grau de profissionalismo e sobre a capacidade de gerenciamento. Essas duas qualidades poderāo ser exigidas simultaneamente, dependendo da catcgoria ocupacional.

$O$ rápido desenvolvimento tecnológico, turistas mais cxigentes e condiçōes conjunturais cada vez mais $\mathrm{cm}$ transformaçà) (como desafios ecológicos e sociais) precisam de aperfeiçoamento c trcinamento inicial permanente, a fim de proporcionar uma sólida formaçáo dos intcgrantes das ocupaçōes turísticas.

A complexidade e a necessidade de uma abordagem interativa dos problemas e a análise dos "feedbacks", requerem um modo de pensamento analítico e sintético, e de açāo ( global c integrado) significando a inclusāo simultânea de dados cconômicos, sociais e ecológicos, dentre outros. Isso quer dizer que a tcoria dos sistemas pode contribuir para clar uma visāo holística, portanto de conjunto, da influência dos supcrsistcmas c subsistemas; facilita, por essa decomposiçāo, a claboraçāo de estratćgias, conforme explicitado no modelo do sistema de turismo já desenvolvido por BENI (1988)

Os modernos cursos superiores de turismo, tanto no Brasil como no exterior, nāo estāo separados da pesquisa, o que impède a formaçāo de executivos distantes da prática. A pesquisa deve promover o profissionalismo pela experiência c pcla formaçāo escolar, c facilitar a soluçāo dos problemas, considerando que:

a) a formaçāo acadêmica em turismo exige estrcita rclaçāo com a prática; b) o treinamento contínuo ganhará maior importância no futuro;

2 Giuseppe Lov Puddu ć professor da Lniversidade Bocconic em Milão. e Presider:te da AMFORT. censino superior de turismo deve. estar voltado para o levantamento o ensino supe (problemas que existem hoje e que devem ser resolvidos de questoes (identificáveis das expressöes da vida social); para a nos setores identago e didática, com a identificação de disciplinas utilizaçao da pelacoos na soluçāo do problema; para o cmprego do método científico, ou seja, a incorporaçāo das modernas teorias científicas.

A crescente internacionalizaçāo do ensino superior de turismo é a nova tendência mundial. A mobilidade de alunos e professores que ela promove corresponde, ademais, à funçào do turismo que ć unir e reconciliar os povos.

\section{ENSINO DE TURISMO E HOTELARIA NO EXTERIOR}

Neste item analisa-se a situaçāo ora vigente no ensino de Turismo e Hotelaria de alguns países da Europa, América do Nortc e América Latina.

\subsection{Europa}

\subsubsection{Alemanha}

A estrutura do sistema educativo alemāo é bastante típica. A cscolaridade obrigatória dura de 9 a 10 anos. $O$ sistema cducacional enfatiza a formaçāo profissional e, neste sentido, ele é dual, ou scja, os jovens se preparam para exercer uma profissāo concorrendo a uma cmpresa e também a uma escola. Aprendem no próprio local de trabalho: em um hotel grande ou pequeno, em uma transportadora, em um restaurante, em uma empresa de planejamento ou em uma agência de viagens; ao mesmo tempo, freqüentam, um ou dois dias por semana, uma escola profissional.

Aumentaram-se as exigências que se impōem a detcrminados ofícios e profissōes e, no caso da empresa hotelcira, só é pcrmitido um contrato de formaçāo dual a egressos de escolas de ensino médio e liceus. Em 1989, por exemplo, cerca de $74 \%$ de jovens da mesma idadc recebiam sua formação profissional no sistema dual, quer dizcr, firmavam com as empresas contratos de aprendizagem, scndo nclas instruídos segundo normas vigentes para cada profissāo. Para a formaçāo, ć obrigatória a freqüência a uma escola profissional de jornada parcial (atć 12 horas-aulas por semana), onde recebem o ensino profissional corrcspondente. A 
capacitaçāo prática nas empresas é regulamentada por lei fcederal. e a formaçào térica nas escolas profissionais é regida pelas lcis de ensino das respectivas províncias alemāes. A aprendizagem dura, $\mathrm{cm}$ geral, 3 anos e é concluida através de exame reconhecido pelo Estado, feito perante bancas examinadoras cujos membros são representantes do patronato e professores de escolas profissionais.

A formaçāo em um hotel ou restaurante pauta-se no princípio de aprender fazendo. A atividade deve permitir ao jovem aprender passo a passo a realizar por si só trabalhos cada vez mais complexos. No plano geral da formação e em especial, no plano de formaçāo da empresa acham-se estipulados os trabalhos que o aprendiz deve executar e quais as atividades com que deve se familiarizar. ()s conhecimentos e capacidades estāo distribuídos de forma diferente, segundo a área de capacitaçào e o tamanho do hotel ou restaurante.

No hotel ou restaurante - seja pequeno ou grande - os jovens se familiarizam em distintas áreas de atividades, de acordo com um plano de formaçāo elaborado para cada caso concreto. Eles normalmente começam nos departamentos de banquetes e de serviços, porque são os mais difíccis e trabalhosos. Passam depois por outros departamentos como de gerência, cozinha, compras, vendas, recepçāo e administraçāo.

Sob a direçāo de instrutores profissionais e semi-profissionais, aplicam o aprendido e enriquecem suas capacidades e conhecimentos. Existem muitos hotéis que dāo a seus aprendìcs aulas suplementares, além daquelas da escola profissional. Se os hotéis e restaurantes pequenos nào tiverem todos os departamentos, que sāo obrigatórios segundo o plano geral de formaçāo, os hotés grandes accitam os jovens dos hotéis de pequeno porte. Desse modo, os aprendizes familiarizam-se também com os trabalhos que nào sào feitos em scus hotéis.

Todo jovem está obrigado a freqüentar uma escola profissional durante seu período de formaçāo. () hotel tem de dcixar ao aluno tempo livre para as aulas, sem descontá-lo do salário. A funçāo da escola profissional consiste em complementar a for maçāo recebida no hotel. Por isso, cerca de $69 \%$ da atividade pedagógica é ensino especializado. No entanto, os professores das escolas profissionaistambém devemestimular a cultura geral dos alunos, e o programa de ensino inclui matérias como línguas estrangeiras, ciências sociais e economia.

Apenas os custos de formaçào que sāo repartidos entre as escolas sảo pagos com fundos fiscais, já que os alunos nảo pagam matrícula. $O$ financiamento das escolas profissionais está estipulado de tal maneira que os professores sảo remuncrados, em geral, pela província respectiva, enquanto os municípios se encarregam das despesas com a manutençāo dos prédios escolares, outras instalaçōes c pessoal administrativo.
Alongou-se propositadamente o caso da Alcmanha, pelo fato da Alongou-se pro educaçāo formal, complementada, ou melhor, tendo singularidade de suá no exercício profissional. Isso facilita a formação da sua principal parte já prontamente empregada.

Muitos profissionais desse nível, entretanto, após o exame final Muitos pro formação no nível superior. Tratando-se da Alemanha, continuam sua for esquecer que lá a fonnaçäo profissional, lá séculos, é vista como investimento para o futuro.

\subsubsection{Espanıa}

Esse país iniciou, a partir de fins de 1989, uma completa revisāc dos cursos de turismo, visando uma maior qualidade na preparaçāo dos profissionais da área. () ensino de turismo só foi régulamentado cm 1980 e, na realidade, justifica essa transformaçāo. Para freqüentar um curso de turismo é exigida educaçào secundária complcta. ()s estudos duram três anos e conferem a obtençāo do título de Técnico de Empresas e Atividades Turísticas, com valor acadêmico igual ao do diplomado universitário.

A carreira desse técnico é concebida como uma formaçāo polivalente para profissionais do setor de turismo, dirigida especificamente à preparaçāo de técnicos e dirigentes de agências de viagens, administradores de hotelaria e guias turísticos. Pode ser obtida especialização maior em cursos de pós-graduação. ()s cursos de (iestáto de Agências de Viagens ou de excrcício profissional como (juias de Turismo duram um ano, e sāoúnicos. No sctor hotelciro a oferta ć um pouco maior. Além do Curso de Alojamentos e Restaurantes da Escola ()ticial de Turismo, há o ('urso de Gerência Hoteleira da Universidade Politécnica de Madri. Só recentemente têm surgido alguns projetos e/ou experiências ainda pouco definidos em outras universidades. Na realidade, os estudos de turismo podem ser feitos na Escola ()ficial de Turismo e em cerca de cinqüenta escolas nāo-oficiais em várias cidades espanholas.

A situação dos graduados em turismo com relaçāo ao cmprego é melhor que na maioria das out ras carrcilas de ensino superior c, de modo geral, não têm grandes dificuldades cm integrarem-sc nas cmpresas do setor. O desemprego ć raro.

Mas isto não significa que a formação at ual scja perfeita. A revisāo referida no início deste item deve responder importantes questōs, tais como:

a) necessidade de maior diversilicaçāo dos estudos, pois nào requerem a mesma formaçāo os guias turísticos. os técnicos e dirigentes da 
atividade hoteleira, técnicos de transporte, de scrviços comerciais, de informaçāo e assistência direta aos viajantes;

b) tempo de duraçāo dos estudos para funçōes técnicas de nível médio, de nível superior e carreiras profissionais de maior responsabilidade técnica e diretiva;

c) os conteúdos dos programas de estudos precisam atender ao contínuo processo de modernizaçāo ná tecnologia das comunicaçòes e o rá pido ritmo de mudança nas caractcrísticas do turismo e dos luristas; além disso, devem estar compabilizados com exigências de formał̧ào especializada cm administraçāo empresarial moderna, com ênfase na particularidade da gestāo de empresas turisticas específicas; compete aqui aos empresários uma contribuiçāo maior, proporcionando informaçōes detalhadas sobre as ocupaçōes específicas de nível técnico e de dircçāo existentes nas empresas, os conhecimentos c capacidades que demandam ou que vāo exigir no futuro imediato e suas políticas de recrutamento de pessoal;

d) formaçāo tcórica e prática, em termos de duraçāo, conteúdo e condiçōes da prática;

e) as características dos centros de formaçāo, visando reforçar o modelo atual de escolas de nível superior independentes ou incluir os cursos de turismo na Universidade;

f) a colaboraçāo de empresários e de profissionais na revisão dos cursos de turismo.

\subsubsection{França}

A formaçāo superior $\mathrm{cm}$ turismo nas universidades francesas iniciou-se em 1961, com a criaçāo do Centro de Estudos Superiores de Turismo na Faculdade de Letras e Ciências Humanas de Paris, precedendo assim a criaçāo de vários seminários sobre turismo nas univcrsidades.

Em 1976 criam-se a licenciatura e a pós-graduaçāo em turismo, colocadas em prática entre 1980 e 1892 nas Universidades de Paris I, Lyon II e Angers. Em 1984 elaborou-se curso de hotelaria, definido em 1985 implantado nas Universidade de Toulouse (198(1), Strasbourg (1987) e Chambery (1988). Paralelamente surgiram cursos científicos é técnicos de conteúdo mais turístico que hoteleiro, cm muitas universidades, tais como as de Lille, Clermont-Ferrand e Angers.

Detcrminadas profissōes (guias, intérpretes, recepcionistas, funcionários alfandegários etc.) nāo têm sua formaçāo na universidade, mas em estabelecimentos de ensino secundário ou em cscolas profissionais de nível pré-universitário. (Os curso supcriores de turismo preparam para profissōes de hotelaria e de restauraçāo, e objetivam uın determinado setor

de atividades profissionais. Podem ser agrupados em três catego-

rias:

a) cursos gerais polivalentes: englobam os principais aspectos da atividade a) cursos gerais ponhecimento e análise do fato do turismo; gestão e prática turistica: conhética de línguas vivas; história e economia do turismo; profissional; prática dé línguas vivánión sociologia; contabilidade; geografia e ordenação do territorio; sociologia, contabilidade; georketing; direito; cartografia; comunicaçao; relaçocs públicas. A Universidade de Lyon II introduziu a disciplina de introduçaio à pesquisa;

b) cursos orientados para $u$ um setor de atividades ligadas ao turismo: promoçāo, animaçāo e ambiente turístico, c criação e gestão de produtos turísticos;

c) cursos de especialização em lın ano: economia do turismo, gestão e administraçāo turística e hotclcira, c análise cconômica das instituições de lazer, entre outros.

Os cursos superiores franceses de turismo caracterizam-se pela multidisciplinaridade; internacionalizaçāo; motivaçāo dos cstudantes; adaptabilidade, mobilidade e alternância (tcoria c prática); parceria com as empresas turísticas; pesquisas.

\subsubsection{Países Baixos}

Os Países Baixos têm cursos superiores nas áreas de turismo, recreaçāo e lazer. A educaçāo em nível superior iniciou-sc cm 1964, com a criaçāo do Instituto Holandês para Estudos de Turismo, Lazer e Transporte, em Breda. Dez anos depois, começaram os cursos de nível médio de treinamento vocacional. Tanto a Holanda quanto a Bélgica têm escolas de hotelaria e de cntretenimento. Esses cursos de nível médio sāo particulares e têm por objetivo formar pessoal para agências de viagens, centros de turismo, e recepçāo de hotéis c centros recrcativos.

O conteúdo do curso do Instituto Holandês comprecende as scguintes principais árcas de cstudo: administraçāo do turismo cmissivo e organizaçāo de viagens; administraçāo do turismo receptivo c doméstico e recreaçāo; administraçāo das atividades de làcr; relaçōes públicas c publicidade; estabelecimento de políticas de turismo, pesquisa e planejamento; guia nacional do turista. Está para entrar em atividade mais uma área: a de administraçāo de serviços.

Em 1990, cerca de 12 mil pessoas dedicavam-sc a algum tipo de estudo em turismo, recreaçāo e lazer. Essas atividades têm caráter sazonal e mais de .300.010 trabalhadores estāo empregados em tempo parcial, 
embora exista um pequeno desemprego. Estima-se, hoje, a necessidade holandeza de profissionais de turismo e recreação em torno de 2.500 por ano.

\subsubsection{Inglaterra}

Esse país, como os outros europeus, têm cursos superiores e pro. fissionalizantes com estágio em empresas nas seguintes áreas: agência de viagens; operadoras de turismo; lazer; atrativos; recreação; equipamento hoteleiro e extra-hoteleiro; recepção e outros. Forma pessoal desde o nível médio até o de pós-graduação, e abarca virtualmente todo os setores da atividade turística, que continua em expansão, absorvendo toda a mão-de-obra para tanto qualificada.

$\mathrm{O}$ ensino superior está voltado mais para três grandes áreas de formação: turismo; lazer; hotelaria e entretenimento. O contcúdo, qualidade e êxito dos cursos atendem as necessidades dos alunos e da indústria turística. Centralizam-se bastante na prática e aproximam-se o máximo da realidade empresarial. Um recente e notável desenvolvimento foi a criação de um grupo de empregadores hoteleiros, representando as maiores cadeias de hotéis, que financiam e influenciam o programa educacional para a indústria hoteleira e de recreação.

A análise do conteúdo dos cursos de turismo revela as seguintes áreas: impacto econômico, social c ambiental do turismo; of erta de turismo, com planejamento c estudos de destinação, bem como estudos das indústrias de recreação e entretenimento, hotelaria e transportes; marketing nas viagens de negócios e no turismo, abrangendo estudos da demanda; história do turismo.

\subsubsection{Itália}

Nesse país, que congrega alguns dos maiores pesquisadores e teóricos do turismo, a questão do ensino superior ainda busca sair de suas especificidades regionais e até locais para atingir uma generalidade nacional, ainda que não completa.

Por incrível que pareça, a Itália é um caso atípico no panorama mundial e europeu: não tem a economia do turismo como disciplina regular nem no currículo de uma faculdade de cconomia nem em outras faculdades. Existem poucas pessoas encarregadas de ministrar o curso de Economia do Turismo, ou de um curso de caráter jurídico sobre turismo, e isto num número reduzido de universidades.

Em 1974, o professor Alberto Sessa iniciou o Curso de Especialização em Turismo na Universidade Livre Internacional de Estudos Sociais,
Roma, dentro do Instituto de Economia Política, onde já havia desde Especialização em Economia do Turismo, com duração 1963 o curso de Esa à Faculdade de Economia e Comércio da Univerde um ano, agrega

sidade de Florença.

Em 1970 foi criado um Curso de Aperfeiçoamento na Escola de Estudos Turísticos em Rimini, dependente da Faculdade de Econonia Comércio de Bolonha LUISS, uma universidade sidade C
turismo.

Há, na Universidade de Veneza, uma escola que se destina à formação de operadores dos serviços turísticos, com ênfase maior na economia; escola semelhante foi criada na Universidade de Florença. Já a Faculdade Livre de Ciências Turísticas em Nápoles é a mais antiga instituição a oferecer cursos superiores de turismo. A partir de 1987 , acrescentou-se o Curso de Administração Hoteleira à estrutura curricular da Escola Internacional de Ciências Turísticas em Roma.

A teoria e a educação estão estreitamente ligadas à pesquisa básica e à pesquisa aplicada, e estas não foram bem formuladas para o desenvolvimento do turismo italiano. A Itália ainda está em busca da filosofia que deve embasar o ensino do turismo em suas escolas de nível superior, e começa a ensaiar os primeiros passos na teoria sistêmica para responder às exigências atuais de formação e capacitação de mão-de-obra na área.

\subsubsection{Suiça}

O modelo suiço de ensino superior é regido pelo "espírito" de Glion. Trata-se do Centro Internacional de Glion, situado em Groyère, com trinta anos de experiência, que criou uma simbiose perfeita entre o ensino de turismo e a realidade da profissão. Professores e colaboradores desenvolvem uma atividade de direção e gestão, que oferece aos alunos os frutos de uma experiência continuamente atualizada.

Esse centro criou instalaçôes turísticas receptivas, de restauração e outras que demonstraram a interdependência entre a teoria e a prática Tais instalações constituem uma garantia para a atualização contínua da formação de pessoal, proporcionando aos jovens estudantes não só conhecimentos tecnológicos, mas também desenvolvendo neles o espírito profissional que os torna capazes de adptarem-se às exigências da realidade. Esse é o "espírito" de Glion.

Consciente dos efeitos que as estratégias norte-americanas causaram na hotelaria européia com o sucesso espetaculár da utilização de tecnologias e de métodos de comunicação e de trabalho (administração), 
de promoçāo de vendas, de gestiāo dos recursos humanos e da experiência adquirida, o Centro Internacional de Glion revisa sempre o conteúdo de seus cursos e os métodos de ensino profissional superior. Aos result ados positivos desse centro, acrecentam-se também os da Escola de Lausanne.

$\mathrm{Na}$ Suiça, onde o turismo representa, depois de dois séculos, um dos pilares de sua economia, a questāo dos recursos humanos é prcocupação constante das empresas, conforme revelada por pesquisas feitas pela sociedade suiça de hotelciros. As cmpresas turísticas suiças apoiam concretamente os centros de formaçāo superior.

Deve-se chamar atenção para o fato de que a teoria dos sistemas aplicada ao turismo está sendo objeto de experimentaçāo na Suiçà, na Itália e na Alemanha, e que muitos países da Europa, principalmente os ocidentais, justamente por causa da Comunidade Européia, estāo desenvolvendo programas de ensino superior integrado, visando a internacionalizaçāo da educaçāo em turismo.

\subsection{América do Norte}

\subsubsection{Canadá}

O Canadá vem se destacando através da Universidade de Calgary, no Estado de Alberta, pela criaçāo do (entro de Ensino e Pesquisa de Turismo Mundial, com as seguintes atribuiçōes: servir de instrumento de intercâmbio regular de informaçōes entre todas as faculdades c departamentos sobre programas atuais e futuros, c iniciativas no campo dos estudos de turismo; proporcionar um mecanismo de coordenaçāo das atividades de ensino, pesquisa e serviços turísticos; intermediar contatos e convênios com organizaçōes particulares, como, por exemplo, o Consórcio para Estudos Integrados de Turismo c Hotclaria de Calgary.

Sob a orientaçāo do professor Brent Ritchic, () Canadá também vem desenvolvendo projetos experimentais com modelos sistêmicos de turismo.

\subsubsection{Estados Unidos}

É quase impossível tentar sintetizar o que ocorre nos Estados Unidos na formação supcrior $\mathrm{cm}$ turismo c hotclaria. Por não haver uma instituiçāo específica, cis que esses estudos estāo presentes em todias as universidades sob títulos de disciplinas diversas. Scgundo a visāo norteamericana, isto é assim porque o campo do turismo é muito amplo.

A entidade que mais se destaca em educaçāo de turismo é a Universidade George Washington. Mas não sc obteve até agora um consenso no país sobre o posicionamento apropriado - (acadêmico ou consenso no país sobromas educacionais de turismo.

Os programas de ensino profissionalizante cstão cm ampla expanOs programas de necessidades de pessoal de agências de viagrens, säo e voltados para as necesidadas funções das cmpresas aéreas. $O$ hotéis, restaurantes e determinadas funçōes das cmpresas aéreas. cu ículo compreende reservas e vendas de passagens aéreas, informacōes sobre destinaçōes turísticas, alimentaçao, hotéis, rotciros turísticos, gōes sobre destinaçaça, aluguel de carros, "arte" de vender e treinamentı de computador.

Apenas recentemente o ensino de turismo adentrou nas faculdades e universidades. E, como área de estudo acadêmico, está na "infância". O e univento do turismo como um todo, em nível de ensino superior, é raro de se encontrar. Quando se referem à palavra turismo ou viagem, muitos dirigentes acadêmicos associam o termo a agências de viagens porque acham que ele é funçāo técnica.

Não existe, enfim, nos Estados Unidos como um todo a preocupacāo de abordar holisticamente o) turismo, apesar dc, bem recentemente, tal quadro estar começando a passar por grande transformaçāo. em direçāo talvez a modelos mais curopeizados, o que é demonstrado pela utilizaçāo da teoria dos sistemas.

O México por sua história e constituição demográfica, identifica-se mais com os países latino-americanos e será tratado a seguir.

\subsection{América Latina}

\subsubsection{México}

O México, com grande afluência de turistas, principalmente dos Estados Unidos, em 1989 nāo registrava nada de organizado para o turismo receptivo. Estava estudando o problema c a mancira pela qual podia ser solucionado para, depois, aplicar as estratćgias adequadas. Um dos resultados do estudo foi que $90 \%$ dos empregos gerados pelo setor de turismo estavam na área de restaurantes, alimentos e bebidas, c os restantes $10 \%$ em agências de viagens, transportes, aluguel de aut(ımóveis, guias e assitência jurídica. Esses dados apontaram onde deveriam ser enfocados estudos mais detalhados e esforços para capacitar a māode-obra. Constatou-se que $78 \%$ dos empregos exigiam nível basico, $16 \%$ nrvel Intermediário e apenas $6 \%$ nível superior ou de direção.

Ficou patente que a área de serviços precisava de capacitação e atualizaçāo profissional, sendo que o principal obstáculo para isso residia no próprio empresário. 
Houve que se iniciar no México uma "reviravolta", pois esse país tem enorme turismo emissivo, e precisava convencer urgententemente os próprios agentes de viagens para trabalharem em defesa do turismo receptivo internacional e doméstico; ensiná-los, ainda, a como venclè-lo e comercializá-lo. Isso foi conseguido, em parte, oferecendo cursos de 30 horas para duas categorias: hotelaria e agência de viagens. Não foi exigido, para isso, formaçào acadêmica, mas cxperiência a nível gerencial.

Existiam no país, em 1989, 225 escolas com diferentes sistemas de capacitação e 70 mil alunos inscritos, c apenas $20 \%$ dos cgressos aproveitados no setor produtivo. As autoridades responsáveis pela educição chegaram à conclusão, nesse mesmo ano, que as escolas deveriam reestruturar seus programas para atender as necessidades reais do mercado turístico, e que havia necessidade de ser criada uma instituição de ensino com equipamentos c instalaçōes exigidos para o estudo do turismo.

Outra questào é a da formaçào dos próprios professores, bem como a ausência de definição de planos e programas para a atividadde, visto que o México ainda vive a problemática da divisão entre a educaçāo em turismo e o setor empresarial.

\subsubsection{Colômbia}

Os dados sobre a Colômbia cmbora divulgados em 1989, referemse ao ano de 1983, quando existiam 27 institutos particulares e um público dedicado à formaçào superior em turismo e hotelaria. ()s primciros formaram 3.956 pessoas, das quais cerca de $19,0 \%$ correspondiam ao nível universitário, $12,5 \%$ ao tecnológico e $68,5 \%$ a a profissional intermediário.

Estudo realizado em 1983 entre os formados pelo programa Gerência Hotelcira e de Turismo da Universidade Extcrnado da Colômbia permitiu estabelecer, de um total de 4.510 empregos diretos gerados pelas agências de viagens, que 39,6\% dos empregados tinham capacitação profissional e $60,4 \%$, tinham experiência mas nào capacitação. Dessses $39,6 \%$ empregos capacitados, $34 \%$ dos empegados provinham de instituiçōes de capacitação turística e/ou hoteleira, $46 \%$ de agências de viagens e o restante de outras fontes.

As principais conclusōes desse estudo foram a necessidade de realizar investigaçòes específicas sobre a of erta e a demanda da formaçào educacional em turismo e sua resposta no mercado de trabalho, além da unificaçāo de critérios nessa formaçāo buscando-se homogeneizar os programas de capacitaçào profissional.

\subsubsection{Venezuela}

Venezuela, a Universidade Nacional Experimental "Francisco Miranda", em Coro, Estado de Falcón, elaborou c implementou, em de Miranda", Instituto Latino-Americano de Capacitação Turística, conjunto com o formação em turismo cm nível supcrior, dirigidos à cspeprogramáa de técnicos de grau superior universitário e à formaçàio de cializaçáo des. Seus primciros formandos foram em 1989, que também é o ano para o qual se dispóc de dados.

Alguns dos títulos das disciplinas desses programas, são: técnicas de animaçāo em espaços abertos; produtividade das empresas turísticas; estratégias de uso do patrimônio turístico; gerência financeira; sistemas e métodos de gerência; comercialização do produto turístico; formul.tção) e avaliaçāo de projetos turísticos; hotclaria e conjuntos recreacionais; administraçāo de empresas de serviços turísticos; desenvolvimento e coordenação de programas de animação e recreação; organizaçiào e planejamento do turismo; métodos de pesquisa e quantificação turística; planejamento e desenvolvimento de regiôes e pólos turísticos; ordenaçào do espaço urbano para o turismo; organizaçào e gestāo públici do turismo; marketing; formaçāo de recursos humanos; técnicas de conservaçāo e preservaçāo arquitetônica; incorporaçāo de muscus c atividades culturais ao turismo; fontes termais e seu preparo para uso tcrapêutico e recreacional; e muitos outros de impressionante atualidade.

\subsubsection{Argentina}

A Argentina, em comparação com os out ros países latino-americanos, destaca-se por apresentar maior número de universidades e instilutos superiores (públicos e privados), que conferem

desde o nível universitário até o pré-universitário ou intermediário, em turismo.

Para ter-se uma visão da formação de recursos humanos habilitados para as atividades de turismo, sob a responsabilidade das 11 universidades e 11 institutos superiores não-universitários nesse país, passa-se a clencar algumas instituiçōes.

\section{a) Universidades}

- Universidade Nacional de Mar del Plata - Faculdade de Ciências Econômicas e Sociais, formadora de hacharéis c'm turismo. 
- Universidade Nacional da Patagônia "San Juan Bosco" - Céntro Austral de Investigaçōes Científicas, em Ushuaia, formadora de bacharéis em turismo, técnicos em turismo e recreação, e guias de turismo.

- Universidade Argentina "John F. Kennedy" - Escola de Demografia e Turismo, na Capital Federal, formadora de bacharćis em demografia e turismo.

- Universidade do Salvador, na Capital Federal - Faculdade de História e Letras, formadora de bacharéis $\mathrm{cm}$ turismo, técnicos em turismo, especialistas $\mathrm{cm}$ turismo c assessores $\mathrm{cm}$ turismo.

- Universidade Católica de Cuyo, em (jodoy Cruz, Mendoza Faculdade de Ciências Empresariais, formadora de bacharćis em turismo e guias de turismo.

- Universidade "Santo Tornás de Aquino" Católica de Tucumán Faculdade de Ciências Administrativas, formadora de bacharćis em administraçāo de empresas com orientaçāo em turismo, administradores de empresas com orientaçāo turística e guias de turismo.

\section{b) Institutos superiores não-univeristários}

- Instituto Superior de Turismo "Perito Moreno" na Capital Federal, formador de técnicos superiores em turismo, técnicos superiores em administraçāo hoteleira, guias superiores de turismo, tćcnicos superiores em gastronomia hotelcira e professores de turismo.

- Escola Superior de Turismo e Hotelaria, cm Córdoba, formadora de técnicos superiores de turismo e hotelaria c guias superiores de turismo.

- Colégio Nacional de Villas Carlos Paz, na província de Córdoba, formador de técnicos em turismo e guias de turismo.

- Instituto Superior de Turismo e Hotclaria "Ilhas Malvinas", em Mendoza, formador de técnicos superiores em turismo e hotclaria, e guias nacionais de turismo.

- Escola de Bibliotecologia "Mariano Moreno", em San Juan, formadora de guias turísticos e culturais de San Juan.

\section{CONCLUSÃO}

Considerando-se o que ocorre na atualidade, com a aplicaçāo de esforços no estudo de outros modelos de formaçāo c capacitaçāio de māo-de-obra em turismo, verifica-se que os principais centros educacionais brasileiros nāo estāo muito distanciados de outros países da Europa e das Américas, que passam hoje por uma fase de reavaliação programática.

O que deve ser ressaltado é a importância de se manter um intercâmbio permanente de experiências, já que as técnicas de ensino variam muito, dada à própria dinâmica do setor de turismo. Nesse sentido, a AMFORT - Associação Mundial para a Formaçāo Profissional Turística tem sido grande instrumento e elemento convergente dessa preocupaçāo e desse intercâmbio.

\section{BIBLIOGRAFLA}

ANNAIS

ros)

BENI, Mário Carlos . 1988. Sistèna de turismo - Construcão de um modelo tcórico referencial para aplicação na pesquisa de tu ECA/USP

CADERNOS

REVUE DE TOURISME. 1990. 1991. Sain 